\title{
Comparison of Effects of Tooth Extraction and Air-rotor Stripping Therapy on Tooth-size Discrepancy in Class I Borderline Patients
}

${ }^{1}$ Demet Kaya, ${ }^{2}$ Tülin Taner, ${ }^{3}$ Derya Germeç-Çakan

\section{ABSTRACT}

Aim: The objectives of this study were to investigate the effects of tooth extraction and air-rotor stripping therapy on tooth-size discrepancy, and to compare the changes between two groups.

Materials and methods: The sample comprised the pre- and post-treatment dental models of 20 postadolescent class I borderline patients. First group was composed of dental models of 10 patients (mean age of $17.1 \pm 2.5$ years) treated with four first premolars extraction. Second group included dental models of 10 patients (mean age of $18.8 \pm 2.7$ years) treated with air-rotor stripping. Treatment effects on Bolton overall and anterior ratios/ values were analyzed by paired sample t-test and independent sample t-test was used for intergroup comparisons.

Results: The change in Bolton overall ratio was found statistically significant for the extraction and insignificant for the air-rotor stripping group. A statistically significant decrease was observed in Bolton anterior ratio for the air-rotor stripping group. Neither four premolars extraction nor air-rotor stripping therapy created statistically significant changes in Bolton overall/anterior values. The changes in Bolton overall ratio/value did not show a statistically significant difference between the groups.

Conclusion: This study showed that tooth extraction or air-rotor stripping therapy did not have an unfavorable effect on toothsize discrepancy in class I borderline patients.

Keywords: Tooth extraction, Air-rotor stripping, Tooth-size discrepancy, Class I, Borderline patients.

How to cite this article: Kaya D, Taner T, Germeç-Çakan D. Comparison of Effects of Tooth Extraction and Air-rotor Stripping Therapy on Tooth-size Discrepancy in Class I Borderline Patients. Int J Experiment Dent Sci 2014;3(1):8-13.

Source of support: Nil

Conflict of interest: None declared

${ }^{1}$ Clinical Instructor, ${ }^{2}$ Professor, ${ }^{3}$ Associate Professor

${ }^{1}$ Department of Orthodontics, Faculty of Dentistry, Karadeniz Technical University, Turkey

${ }^{2}$ Department of Orthodontics, Faculty of Dentistry, Hacettepe University, Turkey

${ }^{3}$ Department of Orthodontics, Faculty of Dentistry, Yeditepe University, Turkey

Corresponding Author: Demet Kaya, Clinical Instructor Department of Orthodontics, Faculty of Dentistry, Karadeniz Technical University, Turkey, Phone: 904623774759, e-mail: ortodem@hotmail.com

\section{INTRODUCTION}

A certain ratio between the sum of mesiodistal crown widths of maxillary and mandibular teeth is necessary for an ideal occlusion. The presence of a tooth-size discrepancy (in ratio or $\mathrm{mm}$ ) between the sum of maxillary and mandibular teeth prevents the establishment of an optimal occlusion. Many studies were done to calculate tooth-size discrepancy in the past. ${ }^{1-5}$ From these studies, Bolton's tooth-size discrepancy analysis became a gold standard in orthodontics. Bolton ${ }^{3,4}$ measured the greatest mesiodistal crown widths of the teeth from first molar to first molar in 55 patients with excellent occlusion. He calculated a ratio by dividing the sum of the mesiodistal crown widths of 12 maxillary and mandibular teeth and found a mean overall ratio of 91.3 $\pm 1.91 \%$ in patients with no tooth-size discrepancy. The mean anterior ratio was $77.2 \pm 1.65 \%$ in the same population. Some of previous studies stated that ratios more than 2 SD (Standard Deviation) from Bolton's mean indicated clinically significant tooth-size discrepancies. ${ }^{6-9}$ If a toothsize discrepancy is detected, it is important 'how large is it?'. The favorable limit for the discrepancy is $1.5 \mathrm{~mm}$ and larger values create treatment problems according to Proffit. ${ }^{10}$

Many factors affect tooth-size discrepancy and, a common factor is tooth extraction. The effect of extraction on tooth-size discrepancy has been studied for years. These studies showed that tooth extraction can influence the overall ratio. ${ }^{11-14}$ However, it is not clear how tooth extraction affect the overall ratio. Some authors stated that the extraction of four first premolars led to a greater tooth-size discrepancy than any other tooth extraction combinations, ${ }^{12}$ but the other studies showed that the extraction of four first premolars resulted in a smaller value of overall ratio. ${ }^{13,14}$ Tong et al ${ }^{13}$ and Endo et $\mathrm{al}^{14}$ found that overall ratios decreased most in the extraction combination of both all second premolars and upper second and lower first premolars.

Most studies evaluating tooth-size discrepancy were carried out on cases treated with tooth extraction. ${ }^{11-14}$ These studies except for designed hypothetically were on clear-cut extraction cases. ${ }^{11}$ The literature comparing the effects of tooth extraction and air-rotor stripping therapies on toothsize discrepancy is lacking. Therefore, the objectives of this study were to investigate the effects of tooth extraction 
and air-rotor stripping therapy on tooth-size discrepancy and to compare the changes between two groups in Class I borderline cases.

\section{MATERIALS AND METHODS}

The study was approved by the Ethical Committee of the Hacettepe University Medical School and informed consent was obtained from each patient before treatment.

The pre- and post-treatment dental models of a former clinical investigation comprised the material of this study. ${ }^{15,16}$ A total of 25 borderline Angle class I patients ( 5 males and 20 females) who equally susceptible to both tooth extraction or air-rotor stripping therapy were included in this study. The inclusion criteria were the following: no skeletal discrepancies, Angle class I molar relationship, completed pubertal growth spurt, good quality of dental models, moderate maxillary and mandibular dental arch crowding, no supernumerary/congenitally missing teeth, no severe mesiodistal/occlusal tooth abrasion, no tooth restoration. Five of the 25 patients were excluded from the study because of different extraction pattern and also to eliminate sexual differences. Finally, the sample comprised of 20 female patients. The sample was randomly divided into two groups. The mean ages and dental arch crowding values of the subjects in both groups are shown in Table 1.

In the first group, 10 patients (mean age of $17.1 \pm 2.5$ years) were treated with the extraction of four first premolars. First, the canines were distalized with sectional arches and without anchorage appliance. The distalization of the canines were maintained untill the correction of crowding. Then, increased labial crown torqued arcwires were used for closing the remaining spaces. Anterior anchorage was increased by means of tying the anterior 4 teeth together. In the second group, 10 patients (mean age of $18.8 \pm 2.7$ years) were treated with the air-rotor stripping technique as reported by Sheridan. ${ }^{17}$ Before treatment, the thickness of enamel for each tooth was assessed on bite-wing radiographs. The air-rotor stripping was performed using a bur kit (Raintree Essix, Metairie, La). After the leveling of posterior teeth, separators were applied between the first molars and the second premolars. When the separation was achieved, mesial enamel surfaces of the first molars and distal enamel surfaces of the second premolars were stripped with 699 LC crosscut fissure tungsten carbide burs and polished with finishing diamond burs and extrathin medium and extrathin fine SofLex polishing disks (3M Dental Products, St Paul, Minn). Then, the distal movement of second premolars was achieved with the aid of open coil springs. An anterior Essix plate was used for anterior anchorage. The technique was performed from posterior to anterior teeth in the same manner. After the canine distalization, the anterior teeth were bonded and ait-rotor stripping was done with fine diamond burs. Fluoride gel was applied topically following air-rotor stripping. No expansion appliances were used in any group. ${ }^{15,16}$ On the pre- and post-treatment dental models of these treatment groups Bolton analyses were performed.

The greatest mesiodistal crown widths of 12 maxillary and mandibular teeth were measured using a digital caliper (Opto-Rs 232 simplex/duplex, Sylvac/Flower, Crissier, Switzerland) on pretreatment plaster models. The caliper tips were positioned parallel to the occlusal surface of the tooth during measurement. The Bolton overall and anterior ratios were calculated using the formula reported by Bolton: ${ }^{3,4}$

(Sum of mandibular $12 \div$ Sum of maxillary 12$) \times 100$ $=$ overall ratio $(\%)$.

$($ Sum of mandibular $6 \div$ Sum of maxillary 6$) \times 100=$ anterior ratio (\%).

Also, Bolton overall and anterior values ( $\mathrm{mm})$ were calculated and it was determined where Bolton excess was localized.

After orthodontic treatment, Bolton overall ratios in both groups and anterior ratio in the air-rotor stripping group were calculated on post-treatment plaster models again. In the extraction group, Bolton overall ratio was measured by substituting zero in place of first premolars that were extracted.

Statistical analysis were performed with the SPSS software package (SPSS for Windows 98, version 10.0; SPSS, Chicago, III). The differences in terms of Bolton overall and

Table 1: Comparison of ages, dental arch crowding measurements, Bolton ratios (\%) and values (mm) between groups before treatment

\begin{tabular}{llll}
\hline & $\begin{array}{l}\text { Extraction group }(n=10) \\
\text { Mean } \pm S D\end{array}$ & $\begin{array}{l}\text { Air-rotor stripping group }(n=10) \\
\text { Mean } \pm S D\end{array}$ & $p$-value \\
\hline Age (year) & $17.13 \pm 2.5$ & $18.8 \pm 2.7$ & 0.17 \\
Maxillary crowding $(\mathrm{mm})$ & $-5.73 \pm 1.4$ & $-5.03 \pm 1.4$ & 0.28 \\
Mandibular crowding $(\mathrm{mm})$ & $-6.02 \pm 1.3$ & $-5.85 \pm 1.5$ & 0.78 \\
Bolton overall ratio $(\%)$ & $91.96 \pm 1.8$ & $92.27 \pm 1.5$ & 0.69 \\
Bolton overall value $(\mathrm{mm})$ & $1.41 \pm 0.9$ & $1.34 \pm 1.0$ & 0.86 \\
Bolton anterior ratio $(\%)$ & $78.65 \pm 2.1$ & $78.40 \pm 1.7$ & 0.78 \\
Bolton anterior value $(\mathrm{mm})$ & $1.06 \pm 0.7$ & $0.78 \pm 0.5$ & 0.34 \\
\hline
\end{tabular}

$\mathrm{SD}$, standard deviation; ${ }^{*} \mathrm{p}<0.05$ 


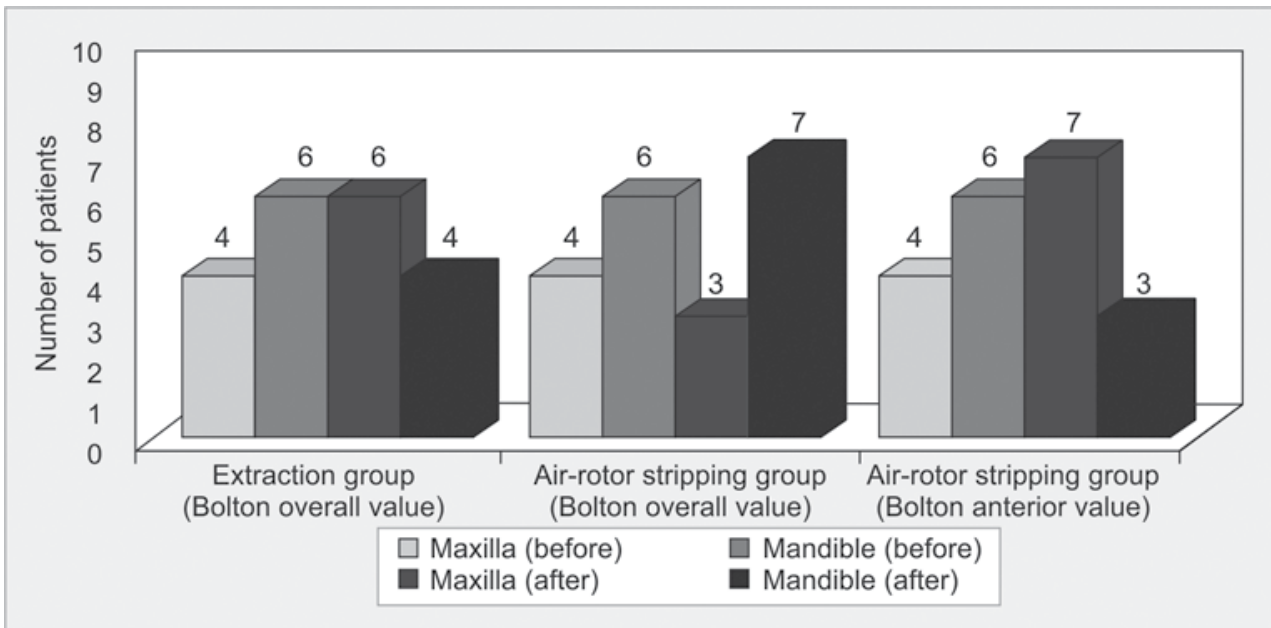

Fig. 1: The distribution of Bolton overall and anterior values in the maxilla and mandible before and after treatment for both groups

anterior ratios/values between the extraction and air-rotor stripping groups before and after treatment were tested with independent sample t-test. Paired sample t-test was performed to test the main effects of treatment on Bolton overall ratio/value in both groups and anterior ratio/value in the second group. Independent sample t-test was used to compare the treatment changes of two groups.

\section{RESULTS}

No significant differences were found between the extraction and air-rotor stripping groups before treatment in terms of age, dental crowding and Bolton overall and anterior ratios/ values (see Table 1).

Table 2 shows that, in the extraction group, there was a statistically significant decrease in Bolton overall ratio. The change in Bolton overall value was not statistically significant. The distribution of pretreatment and post-treatment Bolton overall value in the maxilla and mandible are shown in Figure 1. Although the Bolton overall values of 10 patients were in the maxilla for 4 patients and in the mandible for 6 patients before treatment, they turned out to be 6 in the maxilla, 4 in the mandible after the extraction of four first premolars.

In the air-rotor stripping group, there was a statistically significant decrease in Bolton anterior ratio. The changes in Bolton's overall ratio, Bolton overall and anterior values were not statistically significant (see Table 2). The distribution of pretreatment and post-treatment Bolton overall and anterior values in the maxilla and mandible are shown in Figure 1. Although the Bolton overall values of 10 patients were in the maxilla for 4 and in the mandible for 6 before treatment, they turned out to be 3 in the maxilla, 7 in the mandible after air-rotor stripping. Although Bolton anterior values of 10 patients were in the maxilla for 4 patients and in the mandible for 6 patients before treatment, they turned out to be 7 in the maxilla, 3 in the mandible after air-rotor stripping.

Table 2: Changes in Bolton ratios $(\%)$ and values $(\mathrm{mm})$ for extraction and air-rotor stripping groups during treatment

\begin{tabular}{|c|c|c|c|c|}
\hline Groups & Bolton ratio/value & $\begin{array}{l}\text { Before treatment } \\
\text { Mean } \pm S D\end{array}$ & $\begin{array}{l}\text { After treatment } \\
\text { Mean } \pm S D\end{array}$ & $p$-value \\
\hline \multirow{4}{*}{$\begin{array}{l}\text { Extraction group } \\
(n=10)\end{array}$} & Overall ratio (\%) & $91.96 \pm 1.8$ & $90.49 \pm 2.2$ & $0.00^{*}$ \\
\hline & Overall value $(\mathrm{mm})$ & $1.41 \pm 0.98$ & $1.28 \pm 1.0$ & 0.60 \\
\hline & Anterior ratio (\%) & $78.65 \pm 2.1$ & $78.65 \pm 2.1$ & - \\
\hline & Anterior value (mm) & $1.06 \pm 0.7$ & $1.06 \pm 0.7$ & - \\
\hline \multirow{4}{*}{$\begin{array}{l}\text { Air-rotor stripping } \\
\text { group }(n=10)\end{array}$} & Overall ratio (\%) & $92.27 \pm 1.5$ & $91.82 \pm 1.3$ & 0.33 \\
\hline & Overall value (mm) & $1.34 \pm 1.0$ & $1.11 \pm 0.7$ & 0.49 \\
\hline & Anterior ratio (\%) & $78.4 \pm 1.7$ & $76.94 \pm 1.9$ & $0.00^{*}$ \\
\hline & Anterior value (mm) & $0.78 \pm 0.5$ & $0.87 \pm 0.5$ & 0.69 \\
\hline
\end{tabular}

SD: standard deviation; ${ }^{*} \mathrm{p}<0.05$

Table 3: Comparison of treatment changes between the groups, (post-treatment value-pretreatment value)

\begin{tabular}{llll}
\hline Bolton overall ratio/value & $\begin{array}{l}\text { Extraction group }(n=10) \\
\text { Mean } \pm S D\end{array}$ & $\begin{array}{l}\text { Air-rotor stripping group }(n=10) \\
\text { Mean } \pm S D\end{array}$ & $p$-value \\
\hline Bolton overall ratio $(\%)$ & $-1.47 \pm 0.8$ & $-0.44 \pm 1.3$ & 0.05 \\
Bolton overall value $(\mathrm{mm})$ & $-0.13 \pm 0.7$ & $-0.22 \pm 0.9$ & 0.81 \\
\hline
\end{tabular}

SD: standard deviation; ${ }^{*} p<0.05$ 
Table 4: Comparison of Bolton ratios (\%) and values $(\mathrm{mm})$ between the groups after treatment

\begin{tabular}{llll}
\hline $\begin{array}{l}\text { Bolton overall/anterior } \\
\text { ratio/value }\end{array}$ & $\begin{array}{l}\text { Extraction group }(n=10) \\
\text { Mean } \pm S D\end{array}$ & $\begin{array}{l}\text { Air-rotor stripping group }(n=10) \\
\text { Mean } \pm S D\end{array}$ & $p$-value \\
\hline Bolton overall ratio $(\%)$ & $90.49 \pm 2.2$ & $91.82 \pm 1.3$ & 0.11 \\
Bolton overall value $(\mathrm{mm})$ & $1.28 \pm 1.0$ & $1.11 \pm 0.7$ & 0.66 \\
Bolton anterior ratio $(\%)$ & $78.65 \pm 2.1$ & $76.94 \pm 1.9$ & 0.07 \\
Bolton anterior value $(\mathrm{mm})$ & $1.06 \pm 0.7$ & $0.87 \pm 0.5$ & 0.50 \\
\hline
\end{tabular}

SD: standard deviation; ${ }^{*} \mathrm{p}<0.05$

The comparison of changes in Bolton overall ratios/ values showed that there were no significant differences between the groups (Table 3).

The amount of reduction obtained by air-rotor stripping was $5.81 \pm 1.7 \mathrm{~mm}$ for the maxillary teeth $(2.77 \pm 1.0 \mathrm{~mm}$ for anterior and $3.05 \pm 1.1 \mathrm{~mm}$ for posterior) and $5.86 \pm 1.1 \mathrm{~mm}$ for the mandibular teeth $(2.85 \pm 0.7 \mathrm{~mm}$ for anterior and $3.05 \pm 1.0 \mathrm{~mm}$ for posterior).

Bolton overall and anterior ratios/values were not different between the extraction and air-rotor stripping groups after treatment (Table 4).

\section{DISCUSSION}

Tooth-size discrepancy analysis is helpful in treatment planning of orthodontic patients and in obtaining functional and esthetic outcome. In this study, the major concern was whether four first premolars extraction/air-rotor stripping therapy would contribute to an undesirable effect on Bolton ratio and value. For this purpose, subjects with similar characteristics were selected to obtain comparable groups. Only patients with class I malocclusion who could be equally susceptible to both tooth extraction or air-rotor stripping therapy were included into the study due to statistically significant associations between tooth-size discrepancy and malocclusion types as reported previously. ${ }^{18,19}$ Some evidence points to sexual differences in tooth size and toothsize ratio. ${ }^{13,20-22}$ However, Nie and $\operatorname{Lin}^{23}$ and Ta et $\mathrm{al}^{6}$ did not find any sexual differences in overall ratio. In our study, an attention was given for the selection of female cases only to eliminate this bias. Also, no statistically significant differences in age, maxillary and mandibular crowding, or Bolton overall and anterior ratios/values were observed between the extraction and air-rotor stripping groups before treatment.

The mean overall ratio was found to be $91.3 \pm 1.91 \%$ in patients with excellent occlusion by Bolton. ${ }^{3}$ However, Uysal and Sari $^{7}$ reported that Bolton' ${ }^{3}$ overall and anterior ratios did not represent Turkish people and found norms for overall and anterior ratios in Turkish population. They reported that the mean overall ratio was $91.73 \pm 2.26 \%$ in females. ${ }^{7}$ However, Heusdens et $\mathrm{al}^{24}$ reported that there was no significant difference between the overall ratio of Bolton and epidemiologic studies. He also stated that the anterior ratio in epidemiologic studies was higher than Bolton's anterior ratio due to a greater morphologic variability in maxillary incisor width. In our study, the mean pretreatment Bolton overall and anterior ratios were $91.96 \pm 1.8 \%$ and $78.65 \pm 2.1 \%$ in the extraction group and $92.27 \pm 1.5 \%$ and $78.40 \pm 1.7 \%$ in the air-rotor stripping group. The mean pretreatment Bolton overall/anterior ratios of the groups were in the normal range described by Bolton ${ }^{3}$ and Tancan and Sari, ${ }^{7}$ and did not differ between the groups.

Tooth extraction is often necessary to obtain the best results for patients and the extraction of all first premolars is most common. ${ }^{25}$ In the extraction group, all first premolars were extracted to solve the moderate crowding. The removal of all first premolars reduced the mean Bolton overall ratio from $91.96 \pm 1.8 \%$ to $90.49 \pm 2.2 \%$ significantly. This result was in accordance with the studies reporting that the extraction of four first premolars results in smaller overall ratio. ${ }^{1,4,13}$ In our study, although the Bolton overall ratio was decreased, the change in Bolton overall value after extraction therapy was not found to be significant. In contrast to our findings, Saatci and Yukay ${ }^{12}$ showed that four first premolar extractions increased Bolton overall value. The sexual differences, sample size and malocclusion type may account for the differences between the results of our study and previous studies.

Interproximal enamel reduction with air-rotor stripping is a commonly applied technique to resolve crowding. ${ }^{26}$ Several authors have shown that stripping might be an alternative treatment approach for space-gaining procedures such as arch development (expansion, proclination of the incisors, distalization of the molars) and tooth extraction in borderline patients with moderate crowding and balanced facial profile while preserving the arch dimensions and the facial esthetic. ${ }^{15-17,27}$ An important question in this study is whether the air-rotor stripping therapy would result in an unfavorable Bolton ratio/value in class I borderline cases. The air-rotor stripping technique provided $5.86 \mathrm{~mm}$ of space in the mandibular dental arch and $5.81 \mathrm{~mm}$ in the maxillary arch. The amount of reduction during air-rotor stripping was determined according to tooth morphology, enamel thickness, and convexity of proximal tooth surface. The amount of air-rotor stripping achieved in this study was acceptable according to Heusdens et $\mathrm{al}^{24}$ reporting that total stripping 
amount of more than 1 premolar mesiodistal width affects the final occlusion and creates a malocclusion. The air-rotor stripping therapy did not result in a statistically significant change in Bolton overall ratio, Bolton overall and anterior values whereas it reduced Bolton anterior ratio significantly. However, the mean Bolton anterior ratio after treatment was in the normal range reported by Bolton ${ }^{3}$ and Uysal and Sari. ${ }^{7}$ Although the mesiodistal width of the anterior teeth is involved in the overall ratio, it has mathematically less effect on the overall ratio than the anterior ratio and this factor could account for the statistically significant decrease in Bolton anterior ratio.

When the study groups were compared, the changes in Bolton overall ratios/values during treatment were not statistically different between the groups. Because the comparison of the effects of teeth extraction and air-rotor stripping on Bolton ratio/value is lacking in the literature, our findings could not be compared with the results of other studies. The air-rotor stripping created a smaller size of Bolton overall value than the removal of all first premolars after treatment, but the difference between the groups was not statistically significant. The final Bolton overall value was $1.28 \mathrm{~mm}$ for the extraction group and $1.11 \mathrm{~mm}$ for the air-rotor stripping group. These values were acceptable for a proper occlusal interdigitation according to the literature. ${ }^{11,14,24}$ Saatci and Yukay $^{12}$ found that the extraction of four first premolars created an amount of $1.25 \mathrm{~mm}$ of tooth-size discrepancy. Endo et al. ${ }^{14}$ reported that discrepancy greater than $1.5 \mathrm{~mm}$ indicated a clinically significant tooth-size discrepancy. Based on these informations and the findings of our study, it can be concluded that extraction of four first premolars or anterior and posterior air-rotor stripping from both arches did not adversely affect the proportion of intermaxillary tooth sizes. On the other hand, if the pretreatment Bolton discrepancy values are greater and require to be treated for a proper occlusion, one can choose to solve the crowding using selective stripping or combine extraction therapy with enamel reduction of the problematic teeth. Another alternative to manage tooth-size discrepancy is to create spaces and build-up the undersized tooth dimension. ${ }^{4}$

When the results are evaluated, it should be taken into consideration that this retrospective study has a limitation of small sample size. The reason for the small sample size was the difficulty in creating homogenous groups composed of postadolescent borderline class I cases who equally susceptible to both tooth extraction or air-rotor stripping therapy in terms of moderate crowding and balanced facial profile. Therefore, further studies are needed to investigate the effects of these two treatment modalities with larger samples.

\section{CONCLUSION}

In the present study, the following conclusion may be drawn;

The extraction of all first premolars resulted in a statistically significant decrease in Bolton overall ratio whereas did not change Bolton overall value.

In the air-rotor stripping group, although there was a statistically significant decrease in Bolton anterior ratio, the changes in Bolton overall ratio, Bolton overall and anterior values were not statistically significant.

The comparison of changes in Bolton's overall ratio showed that there were no statistically significant differences between the groups.

This study showed that extraction of four first premolars or air-rotor stripping therapy did not have an unfavorable effect on tooth-size discrepancy (in ratio or value) in class I borderline cases.

\section{REFERENCES}

1. Ballard ML. Asymmetry in tooth size: a factor in the etiology, diagnosis and treatment of malocclusion. Am J Orthod 1944; 14(3):67-71.

2. Black GV. Descriptive anatomy of the human teeth. 4th ed Philadelphia: SS White Dental Manufacturing Co; 1902.

3. Bolton WA. Disharmony in tooth size and its relation to the analysis and treatment of malocclusion. Acta Odont Scand 1958; 28(3):113-130.

4. Bolton WA. The clinical application of a tooth-size analysis. Am J Orthod 1962;48(7):504-529.

5. Neff CW. Tailored occlusion with the anterior coefficient. Am J Orthod 1949;35(3):309-313.

6. Ta TA, Ling JY, Hagg U. Tooth-size discrepancies among different occlusion groups of southern Chinese children. Am J Orthod Dentofacial Orthop 2001;120(5):556-558.

7. Uysal $T$, Sari Z. Intermaxillary tooth size discrepancy and mesiodistal crown dimensions for a Turkish population. Am J Orthod Dentofacial Orthop 2005;128(2):226-230.

8. Araujo E, Souki M. Bolton anterior tooth size discrepancies among different malocclusion groups. Angle Orthod 2003;73(3): 307-313.

9. Freeman JE, Maskeroni AJ, Lorton L. Frequency of Bolton tooth-size discrepancies among orthodontic patients. Am J Orthod Dentofacial Orthop 1996;110(1):24-27.

10. Proffit WR. Contemporary orthodontics. Saint. Louis: Mosby; 1993;158-160.

11. Kayalioglu M, Toroglu MS, Uzel I. Tooth-size ratio for patients requiring 4 first premolar extractions. Am J Orthod Dentofacial Orthop 2005;128(1):78-86.

12. Saatci P, Yukay F. The effect of premolar extractions on toothsize discrepancy. Am J Orthod Dentofacial Orthop 1997;111(4): 428-434.

13. Tong H, Chen D, Xu L, Liu P. The effect of premolar extractions on tooth size discrepancies. Angle Orthod 2004;74(4):508-511.

14. Endo T, Ishida K, Shundo I, Sakaeda K, Shimooka S. Effects of premolar extractions on Bolton overall ratios and tooth-size discrepancies in a Japanese orthodontic population. Am J Orthod Dentofacial Orthop 2010;137(4):508-514.

15. Germec D, Taner TU. Effects of extraction and nonextraction therapy with air-rotor stripping on facial esthetics in postado- 
lescent borderline patients. Am J Orthod Dentofacial Orthop 2008;133(4):539-549.

16. Germec-Cakan D, Taner TU, Akan S. Arch-width and perimeter changes in patients with borderline class I malocclusion treated with extractions or without extractions with air-rotor stripping. Am J Orthod Dentofacial Orthop 2010;137(6):734.e1-7.

17. Sheridan JJ. Air-rotor stripping. J Clin Orthod 1985;19(1):43-59.

18. Sperry TP, Worms FW, Isaacson RJ, Speidel TM. Tooth-size discrepancy in mandibular prognathism. Am J Orthod 1977; 72(2):183-190.

19. Lavelle CL. Maxillary and mandibular tooth size in different racial groups and in different occlusal categories. Am J Orthod 1972;61(1):29-37.

20. Sanin C, Savara BS. An analysis of permanent mesiodistal crown size. Am J Orthod 1971;59(5):488-500.

21. Doris JM, Bernard BW, Kuftinec MM, Stom D. A biometric study of tooth size and dental crowding. Am J Orthod 1981;79(3):326-336.
22. Santoro M, Ayoub ME, Pardi VA, Cangialosi TJ. Mesiodistal crown dimensions and tooth size discrepancy of the permanent dentition of Dominican Americans. Angle Orthod 2000; 70(4):303-307.

23. Nie Q, Lin J. Comparison of intermaxillary tooth size discrepancies among different malocclusion groups. Am J Orthod Dentofacial Orthop 1999;116(5):539-544.

24. Heusdens M, Dermaut L, Verbeeck R. The effect of tooth size discrepancy on occlusion: an experimental study. Am J Orthod Dentofacial Orthop 2000;117(2):184-191.

25. Vaden JL, Kiser HE. Straight talk about extraction and nonextraction: a differential diagnostic decision. Am J Orthod Dentofacial Orthop 1996;109(4):445-452.

26. Sheridan JJ. The physiologic rationale for air-rotor stripping. J Clin Orthod 1997;31(9):609-612.

27. Sheridan JJ. Air-rotor stripping update. J Clin Orthod 1987;21: 781-788. 